\title{
Social Determinants of Health and Tobacco Use in Five Low - and Middle-Income Countries - Results from the Global Adult Tobacco Survey (GATS), 2011 - 2012
}

\author{
Guat Hiong Tee ${ }^{1 *}$, Tahir Aris ${ }^{1}$, James Rarick$^{2}$, Sorina Irimie ${ }^{3}$
}

\begin{abstract}
Background: Tobacco consumption continues to be the leading cause of preventable deaths globally. The objective of this study was to examine the associaton of selected socio-demographic variables with current tobacco use in five countries that participated in the Phase II Global Adult Tobacco Survey in 2011 - 2012. Materials and Methods: We analysed internationally comparable representative household survey data from 33,482 respondents aged $\geq 15$ years in Indonesia, Malaysia, Romania, Argentina and Nigeria for determinants of tobacco use within each country. Socio-demographic variables analysed included gender, age, residency, education, wealth index and awareness of smoking health consequences. Current tobacco use was defined as smoking or use of smokeless tobacco daily or occasionally. Results: The overall prevalence of tobacco use varied from $5.5 \%$ in Nigeria to $35.7 \%$ in Indonesia and was significantly higher among males than females in all five countries. Odds ratios for current tobacco use were significantly higher among males for all countries [with the greatest odds among Indonesian men (OR=67.4, 95\% CI: 51.2-88.7)] and among urban dwellers in Romania. The odds of current tobacco use decreased as age increased for all countries except Nigeria where. The reverse was true for Argentina and Nigeria. Significant trends for decreasing tobacco use with increasing educational levels and wealth index were seen in Indonesia, Malaysia and Romania. Significant negative associations between current tobacco use and awareness of adverse health consequences of smoking were found in all countries except Argentina. Conclusions: Males and the socially and economically disadvantaged populations are at the greatest risk of tobacco use. Tobacco control interventions maybe tailored to this segment of population and incorporate educational interventions to increase knowledge of adverse health consequences of smoking.
\end{abstract}

Keywords: Social determinants - health - tobacco use - global adult tobacco survey

Asian Pac J Cancer Prev, 17 (3), 1269-1276

\section{Introduction}

Tobacco consumption is a recognised modifiable risk factor for non-communicable diseases; and continues to be the leading cause of preventable deaths. Currently, 1.25 billion adults are smokers and nearly six million people die prematurely from tobacco-related causes yearly; or 9\% of deaths globally (World Health Organization, 2009). The majority of these deaths occur in low- and middleincome countries, disproportionally affecting socially and economically disadvantaged populations, and draining many nations' economies. Unless urgent actions are taken to rectify the current situation, tobacco consumption could lead to a billion premature deaths globally during the $21 \mathrm{st}$ century (World Health Organization, 2011).

Smoking is the scourge of the modern world. It kills 10,000 and 200,000 people annually in Malaysia (Ministry of Health Malaysia, 2003) and Indonesia (Global Adult
Tobacco Survey: Indonesia Report, 2011) respectively. Studies have shown that tobacco use is predominantly among males, in economically productive years (25 50 years), markedly higher among people with lower education and lower social status (Laaksonen et al., 2005; Hosseinpoor et al., 2011; Palipudi et al., 2012; Lim et al., 2013, Sreeramareddy et al, 2014).

The World Health Organisation (WHO) provides global policy leadership in tobacco control and encourages countries to adhere to the principles lay out in Framework Convention on Tobacco Control (FCTC) (World Health Organization, 2005). WHO has identified six evidencebased tobacco control measures that are the most effective in reducing tobacco use known as "MPOWER" (World Health Organization, 2008). These measures correspond to one or more of the demand reduction provisions included in the WHO FCTC, and include "Monitoring" tobacco use and prevention policies. In addition, WHO supports

${ }^{1}$ Institute for Public Health, National Institutes of Health, Ministry of Health Malaysia, ${ }^{2}$ Non-communicable Disease, WHO Office, Phnom Penh, Cambodia, ${ }^{3}$ National Institute of Public Health, Regional Centre of Public Health, Cluj, Romania *For correspondence: helentee.gh@moh.gov.my 
Guat Hiong Tee et al

countries in their effort to implement provisions of the FCTC and MPOWER. Five low- and middle-income countries participated in phase II Global Adult Tobacco Survey (GATS) during 2011-2012. Apart from Argentina and Indonesia, Malaysia, Romania and Nigeria have ratified the WHO FCTC (World Health Organization, 2013a). In many countries, population-based surveys on tobacco use are unavailable. In order to strengthen tobacco control strategies and initiatives to combat this modern scourge, comprehensive evidence-based population data are needed. GATS, a nationally representative household survey of adults $\geq 15$ years using standardised protocol enables consistent data collection for participating countries. It can be used as a tool to systematically monitor tobacco use and track key indicators of tobacco control. The data obtained from GATS can be used to compare the social determinants of health and tobacco use within and across different GATS countries. Palipudi et al (2012) and Hosseinpoor et al (2011) had reported social determinants of health and tobacco use in 13 phase I GATS countries and 48 countries participated in the World Health Survey respectively. The objective of this paper was to assess the association of selected socio-demographic variables with current tobacco use in five countries with different economic status participated in the phase II Global Adult Tobacco Survey in $2011-2012$.

\section{Materials and Methods}

\section{Study design and participants}

GATS was conducted in five Phase II countries between 2011 - 2012; Indonesia (2011), Malaysia (2011), Romania (2011), Argentina (2012) and Nigeria (2012). Argentina, Malaysia and Romania are upper-middle income countries, whereas Indonesia and Nigeria are lower-middle income countries (World Bank).

GATS is a cross sectional household survey designed to obtain nationally representative data. Data were collected from non-institutionalised adults aged $\geq 15$ years using a standardised questionnaire, sample design, data collection and management procedures, as well as analysis protocol (Global Adult Tobacco Survey Collaborative Group, 2010a; Global Adult Tobacco Survey Collaborative Group, 2010b; Global Adult Tobacco Survey Collaborative Group, 2010c; Global Adult Tobacco Survey Collaborative Group, 2010d; Global Adult Tobacco Survey Collaborative Group, 2010e). This is to ensure comparability across countries

Table 1. Frequency Distribution of Adults $\geq 15$ Years by Selected Demographic Characteristics in Five Countries

\begin{tabular}{|c|c|c|c|c|c|}
\hline \multirow{3}{*}{ Characteristics } & Indonesia & Malaysia & Romania & Argentina & Nigeria \\
\hline & $\mathrm{n}=8305$ & $n=4250$ & $n=6645$ & $\mathrm{n}=4517$ & $n=9765$ \\
\hline & \multicolumn{5}{|c|}{ Percent $(95 \% \mathrm{CI})$} \\
\hline \multicolumn{6}{|l|}{ Tobacco use } \\
\hline Current tobacco user & $35.7(34.0-37.4)$ & $23.4(21.5-25.5)$ & $26.7(25.0-28.5)$ & $22.2(19.3-25.4)$ & $5.5(4.9-6.3)$ \\
\hline Former tobacco user & $7.3(6.3-8.4)$ & $4.1(3.3-5.1)$ & $12.6(11.6-13.6)$ & $22.3(19.1-25.8)$ & $3.3(2.8-3.8)$ \\
\hline Never tobacco user & $57.0(55.1-58.9)$ & $72.5(70.3-74.5)$ & $60.7(58.9-62.6)$ & $55.5(51.6-59.4)$ & $91.1(90.3-92.0)$ \\
\hline \multicolumn{6}{|l|}{ Gender } \\
\hline Male & $49.9(48.6-51.2)$ & $51.5(49.5-53.4)$ & $48.2(46.3-50.1)$ & $47.6(43.3-51.9)$ & $50.0(48.5-51.6)$ \\
\hline Female & $50.1(48.8-51.4)$ & $48.5(46.6-50.5)$ & $51.8(49.9-53.7)$ & $52.4(48.1-56.7)$ & $50.0(48.4-51.5)$ \\
\hline \multicolumn{6}{|l|}{ Age group } \\
\hline $15-24$ & $24.1(22.7-25.7)$ & $27.7(25.7-29.8)$ & $15.8(14.3-17.5)$ & $24.3(21.6-27.1)$ & $34.4(32.9-35.9)$ \\
\hline $25-44$ & $45.1(43.6-46.6)$ & $41.5(39.4-43.7)$ & $37.6(35.8-39.5)$ & $33.7(30.4-37.1)$ & $43.8(42.3-45.2)$ \\
\hline $45-64$ & $23.7(22.6-24.8)$ & $23.7(22.0-25.5)$ & $29.0(27.5-30.6)$ & $28.5(24.7-32.6)$ & $16.2(15.2-17.3)$ \\
\hline $65+$ & $7.1(6.2-8.0)$ & $7.1(6.1-8.2)$ & $17.5(16.3-18.8)$ & $13.5(11.0-16.6)$ & $5.6(5.0-6.2)$ \\
\hline \multicolumn{6}{|l|}{ Residence } \\
\hline Urban & $50.2(48.8-51.6)$ & $72.1(70.6-73.6)$ & $55.7(53.0-58.4)$ & NA & $37.0(33.9-40.1)$ \\
\hline Rural & $49.8(48.4-51.2)$ & $27.9(26.4-29.4)$ & $44.3(41.6-47.0)$ & NA & $63.0(59.9-66.1)$ \\
\hline \multicolumn{6}{|l|}{ Education } \\
\hline Less than primary & $22.0(19.3-24.9)$ & $10.1(8.9-11.4)$ & $9.3(8.1-10.6)$ & $9.5(6.9-13.0)$ & $36.2(34.4-38.1)$ \\
\hline Less than secondary & $27.2(24.9-29.7)$ & $30.8(28.7-32.8)$ & $33.2(31.2-35.2)$ & $41.8(36.7-47.2)$ & $14.0(12.9-15.2)$ \\
\hline Complete high school & $43.9(40.8-47.1)$ & $46.6(44.4-48.7)$ & $36.9(34.7-39.2)$ & $35.9(32.4-39.5)$ & $43.7(41.9-45.4)$ \\
\hline College or above & $6.8(5.7-8.2)$ & $12.6(10.9-14.5)$ & $20.6(18.7-22.7)$ & $12.8(10.4-15.6)$ & $6.1(5.4-6.9)$ \\
\hline \multicolumn{6}{|l|}{ Wealth Index } \\
\hline Lowest & $14.6(12.4-17.2)$ & $11.9(10.5-13.5)$ & $14.1(12.7-15.5)$ & $18.1(15.2-21.6)$ & $20.5(18.9-22.3)$ \\
\hline Low & $18.6(16.6-20.7)$ & $15.9(14.4-17.6)$ & $17.3(15.9-18.7)$ & $20.3(16.8-24.3)$ & $21.1(19.7-22.7)$ \\
\hline Medium & $23.5(21.4-25.7)$ & $20.6(18.8-22.4)$ & $20.2(18.7-21.7)$ & $21.1(17.4-25.3)$ & $24.6(22.9-26.3)$ \\
\hline High & $21.5(19.4-23.7)$ & $23.0(21.4-24.8)$ & $25.8(24.0-27.7)$ & $32.6(28.2-37.3)$ & $14.4(13.2-15.6)$ \\
\hline Highest & $21.8(18.7-25.4)$ & $28.6(26.2-31.1)$ & $22.7(20.9-24.6)$ & $7.9(6.1-10.1)$ & $19.4(17.5-21.4)$ \\
\hline \multicolumn{6}{|c|}{ Awareness of smoking Health Consequences } \\
\hline Yes & $86.0(83.4-88.2)$ & $92.2(90.9-93.4)$ & $96.3(95.5-97.0)$ & $98.3(97.1-98.9)$ & $82.4(80.9-83.7)$ \\
\hline No & $14.0(11.8-16.6)$ & $7.8(6.6-9.1)$ & $3.7(3.0-4.5)$ & $1.7(1.1-2.9)$ & $17.6(16.3-19.1)$ \\
\hline
\end{tabular}


Table 2. Prevalence of Current Tobacco Use among Adults $\geq 15$ Years by Selected Demographic Characteristics in Five Countries

\begin{tabular}{|c|c|c|c|c|c|}
\hline \multirow{2}{*}{ Characteristics } & Indonesia & Malaysia & Romania & Argentina & Nigeria \\
\hline & \multicolumn{5}{|c|}{ Percent $(95 \% \mathrm{CI})$} \\
\hline Overall & $35.7(34.0-37.4)$ & $23.4(21.5-25.5)$ & $26.7(25.0-28.5$ & $22.2(19.3-25.4)$ & $5.5(4.9-6.3)$ \\
\hline \multicolumn{6}{|l|}{ Gender } \\
\hline Male & $67.1(64.5-69.6)$ & $44.0(40.7-47.3)$ & $37.4(34.8-40.0)$ & $29.4(24.7-34.5)$ & $9.9(8.8-11.3)$ \\
\hline Female & $4.4(3.5-5.5)$ & $1.6(1.1-2.3)$ & $16.7(15.1-18.5)$ & $15.6(12.6-19.2)$ & $1.1(0.9-1.5)$ \\
\hline \multicolumn{6}{|l|}{ Age group } \\
\hline $15-24$ & $26.2(23.6-29.1)$ & $16.7(13.6-20.4)$ & $22.6(18.7-27.0)$ & $20.7(15.7-26.8)$ & $1.5(1.1-2.2)$ \\
\hline $25-44$ & $38.0(35.9-40.1)$ & $29.4(26.4-32.5)$ & $36.3(33.2-39.5)$ & $27.1(21.3-33.7)$ & $6.0(5.1-7.1)$ \\
\hline $45-64$ & $40.5(37.3-43.7)$ & $23.1(20.2-26.3)$ & $28.0(25.6-30.6)$ & $24.0(18.7-30.3)$ & $10.4(8.6-12.6)$ \\
\hline $65+$ & $37.5(33.4-41.8)$ & $16.1(12.1-21.0)$ & $7.6(6.1-9.6)$ & $8.8(5.8-13.1)$ & $12.3(9.0-16.6)$ \\
\hline \multicolumn{6}{|l|}{ Residence } \\
\hline Urban & $32.6(30.4-34.8)$ & $22.9(20.4-25.7)$ & $28.4(26.3-30.7)$ & NA & $4.0(3.3-4.8)$ \\
\hline Rural & $38.8(36.4-41.4)$ & $24.7(22.4-27.2)$ & $24.5(21.8-27.4)$ & NA & $6.4(5.5-7.5)$ \\
\hline \multicolumn{6}{|l|}{ Education } \\
\hline Less than primary & $40.9(37.8-44.0)$ & $21.2(17.3-25.6)$ & $16.8(12.3-22.4)$ & $18.8(12.2-28.0)$ & $6.1(5.0-7.3)$ \\
\hline $\begin{array}{l}\text { Less than second- } \\
\text { ary }\end{array}$ & $37.5(35.1$ - 39.9) & $24.8(21.5-28.4)$ & $28.0(25.1-31.0)$ & $22.7(17.4-28.9)$ & $8.3(6.5-10.5)$ \\
\hline $\begin{array}{l}\text { Complete high } \\
\text { school }\end{array}$ & $33.3(31.4-35.2)$ & $25.2(22.4-28.2)$ & $28.8(26.2-31.5)$ & $24.0(18.8-30.0)$ & $4.4(3.6-5.3)$ \\
\hline College or above & $27.8(23.9-32.2)$ & $15.3(11.6-19.9)$ & $25.5(22.6-28.8)$ & $17.9(11.8-26.3)$ & $4.5(2.9-7.0)$ \\
\hline \multicolumn{6}{|l|}{ Wealth Index } \\
\hline Lowest & $39.6(35.8-43.5)$ & $34.2(29.1-39.7)$ & $26.1(21.8-31.0)$ & $23.5(17.2-31.2)$ & $5.9(4.6-7.6)$ \\
\hline Low & $37.5(35.1-40.0)$ & $25.4(21.4-30.0)$ & $25.4(22.0-29.1)$ & $24.9(18.8-32.3)$ & $5.8(4.7-7.2)$ \\
\hline Medium & $40.0(37.2-42.9)$ & $28.9(24.8-33.3)$ & $26.5(23.0-30.3)$ & $21.9(17.2-27.4)$ & $6.3(5.1-7.8)$ \\
\hline High & $34.3(31.4-37.3)$ & $19.2(15.9-23.1)$ & $29.2(25.6-33.0)$ & $19.7(15.3-25.1)$ & $5.1(3.6-7.2)$ \\
\hline Highest & $28.2(25.5-31.2)$ & $17.3(14.1-21.0)$ & $25.3(22.2-28.8)$ & $23.0(15.2-33.3)$ & $4.2(3.1-5.6)$ \\
\hline \multicolumn{6}{|c|}{ Awareness of smoking Health Consequences } \\
\hline Yes & $33.5(31.7-35.4)$ & $22.2(20.2-24.2)$ & $25.9(24.2-27.7)$ & $21.9(19.0-25.1)$ & $4.9(4.2-5.6)$ \\
\hline No & $49.1(45.6-52.6)$ & $36.3(29.1-44.3)$ & $46.8(36.9-57.0)$ & $34.7(18.7-55.0)$ & $8.8(7.2-10.6)$ \\
\hline
\end{tabular}

in obtaining measures on key tobacco control indicators. A total of 33,482 respondents participated in the surveys. Details of survey methodologies of each country are available in respective country reports (Global Adult Tobacco Survey: Indonesia Report, 2011; Tee at al., 2012; Global Adult Tobacco Survey, Romania 2011; Global Adult Tobacco Survey, Argentina 2012; Global Adult Tobacco Survey: Nigeria Country Report, 2012). Ethical reviews and approval were obtained by each implementing agency from relevant institutions.

\section{Variables included in the analyses}

Current tobacco use is the dependent variable used in this analysis. It was defined as currently smoking or using smokeless tobacco either daily or occasionally (Global Tobacco Surveillance System, 2009). Current tobacco use was assessed using two questions; i.e. 'Do you currently smoke tobacco on a daily basis, less than daily, or not at all' and 'Do you currently use smokeless tobacco on a daily basis, less than daily, or not at all'.

The determinants of smoking used in this analysis were gender (male / female), age (four categories), residency (urban / rural), educational level (four categories), wealth index (five categories) and awareness of smoking health consequences (yes / no). Awareness of smoking health consequences was assessed using the question "Based on what you know or believe, does smoking tobacco cause serious illness?"

Socioeconomic status of respondents was measured using a proxy indicator of wealth index; which was constructed based on a factor analysis of the assets owned by each household, such as electricity, flush toilet, fixed line telephone, mobile phone, television, radio, refrigerator, car, moped / scooter / motorcycle, washing machine, computer and internet access. The wealth index was categorised into quintiles; from one (lowest) to five (highest) (Palipudi et al., 2012).

\section{Data analysis}

Data analysis was performed using SPSS version 18.0 for complex samples. The estimates for prevalence were reported as percentages with $95 \%$ confidence intervals (CIs). The data were appropriately weighted to account for differential probabilities of selection and participation of respondents resulting from using a household as the sampling unit. The association of the selected sociodemographic characteristics wiht current tobacco use were carried out using multivariable logistic regression. Statistical differences were evaluated using confidence intervals. 
Table 3. Odds of Current Tobacco Use among Adults $\geq 15$ Years Using Logistic Regression Analysis in five GATS Countries

\begin{tabular}{|c|c|c|c|c|c|}
\hline \multirow{2}{*}{ Characteisitics } & Indonesia & Malaysia & Romania & Argentina & Nigeria \\
\hline & \multicolumn{5}{|c|}{ OR $(95 \% \mathrm{CI})$} \\
\hline \multicolumn{6}{|l|}{ Gender } \\
\hline Male & $67.4(51.2-88.7)$ & $56.1(38.6-81.6)$ & $3.0(2.6-3.5)$ & $2.3(1.7-3.1)$ & $10.2(7.4-14.0)$ \\
\hline Female (RC) & 1.0 & 1.0 & 1.0 & 1.0 & 1.0 \\
\hline \multicolumn{6}{|l|}{ Age group } \\
\hline $15-24(\mathrm{RC})$ & 1.0 & 1.0 & 1.0 & 1.0 & 1.0 \\
\hline $25-44$ & $2.4(1.9-2.9)$ & $2.7(2.0-3.7)$ & $2.1(1.6-2.8)$ & $1.5(0.9-2.5)$ & $4.5(3.0-6.8)$ \\
\hline $45-64$ & $2.3(1.8-3.0)$ & $1.6(1.1-2.2)$ & $1.3(1.0-1.8)$ & $1.4(0.8-2.3)$ & $7.1(4.6-10.8)$ \\
\hline $65+$ & $1.8(1.2-2.6)$ & $0.7(0.5-1.2)$ & $0.3(0.2-0.4)$ & $0.4(0.2-0.7)$ & $8.0(4.7-13.7)$ \\
\hline \multicolumn{6}{|l|}{ Residence } \\
\hline Urban & $0.8(0.7-1.1)$ & $1.1(0.9-1.5)$ & $1.5(1.2-1.8)$ & NA & $0.6(0.4-0.9)$ \\
\hline Rural (RC) & 1.0 & 1.0 & 1.0 & NA & 1.0 \\
\hline \multicolumn{6}{|l|}{ Education } \\
\hline Less than primary & $2.8(1.9-4.2)$ & $2.9(1.5-5.3)$ & $1.4(0.9-2.2)$ & $1.2(0.5-2.9)$ & $1.7(0.9-3.0)$ \\
\hline Less than secondary & $1.9(1.3-2.6)$ & $2.2(1.4-3.3)$ & $1.2(1.0-1.6)$ & $1.3(0.7-2.4)$ & $2.3(1.3-4.0)$ \\
\hline Complete high school & $1.5(1.1-1.9)$ & $2.3(1.5-3.5)$ & $1.2(1.0-1.5)$ & $1.4(0.7-2.8)$ & $1.5(0.9-2.5)$ \\
\hline College or above (RC) & 1.0 & 1.0 & 1.0 & 1.0 & 1.0 \\
\hline \multicolumn{6}{|l|}{ Wealth Index } \\
\hline Lowest & $1.9(1.4-2.7)$ & $2.6(1.7-4.1)$ & $1.9(1.3-2.7)$ & $1.4(0.8-2.6)$ & $1.0(0.6-1.6)$ \\
\hline Low & $1.6(1.2-2.1)$ & $1.9(1.3-2.9)$ & $1.6(1.2-2.1)$ & $1.3(0.7-2.4)$ & $1.0(0.6-1.7)$ \\
\hline Medium & $1.6(1.3-2.1)$ & $1.7(1.1-2.4)$ & $1.4(1.1-2.0)$ & $1.2(0.7-2.2)$ & $1.3(0.8-2.0)$ \\
\hline High & $1.3(1.0-1.7)$ & $1.1(0.8-1.6)$ & $1.3(1.0-1.7)$ & $0.9(0.5-1.7)$ & $1.1(0.7-1.8)$ \\
\hline Highest (RC) & 1.0 & 1.0 & 1.0 & 1.0 & 1.0 \\
\hline \multicolumn{6}{|c|}{ Awareness of smoking Health Consequences } \\
\hline Yes & $0.4(0.3-0.5)$ & $0.5(0.4-0.8)$ & $0.4(0.3-0.7)$ & $0.5(0.2-1.3)$ & $0.5(0.4-0.6)$ \\
\hline No (RC) & 1.0 & 1.0 & 1.0 & 1.0 & 1.0 \\
\hline
\end{tabular}

OR-Odds Ratio; CI-Confidence Interval; RC-Reference Category

\section{Results}

\section{Respondent profile}

A total of 33,482 households / respondents (one respondent per household) from the five countries participated in the surveys. The sample characteristics for the five GATS countries by gender, age, residency, educational level, wealth index and awareness of smoking health consequences are as shown in Table 1. The sample design in each of the five participating countries was stratified by gender and residence (urban / rural) (except for Argentina); thus the distributions of these two variables reflect the population distributions. There was an almost equal distribution of males and females in all five countries. All countries showed a similar age distribution pattern; i.e. increasing from 15 to 44 years, and decreasing from 45 years; with the highest percentages of the respondents among 25-44 years age group. There were significantly more urban residents in Malaysia and Romania, whereas there were significantly more rural residents in Nigeria. About $10 \%$ of the respondents in Argentina, Malaysia and Romania received less than primary education. In contrast $22 \%$ and $36 \%$ of the respondents in Indonesia and Nigeria received less than primary education respectively. The majority of respondents in all five countries completed high school education. The population distribution of wealth index based on the possession of household assets showed a more or less even distribution except Argentina. Awareness of smoking health consequences varies from $82 \%$ (Nigeria) to $98 \%$ (Argentina).

\section{Cross-country prevalence}

The overall prevalence of current tobacco use varied significantly from $5.5 \%$ in Nigeria to $35.7 \%$ in Indonesia. Similarly, there were great variations in the prevalence of former tobacco users; from $3.3 \%$ in Nigeria to $22.3 \%$ in Argentina (Table 1).

Table 2 shows the prevalence of current tobacco use among adults $\geq 15$ years by selected demographic characteristics. The prevalence of current tobacco use among males varied from $9.9 \%$ in Nigeria to $67.1 \%$ in Indonesia. The variation was much greater among women; from $1.1 \%$ in Nigeria to $16.7 \%$ in Romania. Prevalence of current tobacco use generally decreased with older age groups (45-64 and $\geq 65$ years' age groups) except among older Nigerians where the reverse was true. Rural dwellers had a higher prevalence than urban dwellers in Indonesia (38.8\% rural, 32.6\% urban) and Nigeria (6.4\% rural, $4.0 \%$ urban). There were no statistically significant difference in current tobacco use among urban or rural residents in Malaysia and Romania. By education level, respondents who attained college and above education had the lowest prevalence of current tobacco use in Argentina, Indonesia 
and Malaysia. By contrast, the lowest prevalence of tobacco use was found among the lowest educated Romanians and among those who had completed high school in Nigeria. Similar pattern of current tobacco use was observed when looking at wealth index; respondents who were at the highest wealth index quintiles used the least tobacco except in Argentina. Except for Argentina, there was significantly higher prevalence of current tobacco use among those who were unaware of smoking health consequences.

Table 3 shows the odds of current tobacco use among adults $\geq 15$ years by selected demographic characteristics using multivariable logistic regression. The strongest predictor of current tobacco use was male gender; with great variation across the five countries; i.e. with odds ratios from 2.3 in Argentina to 67.4 in Indonesia. Using the lowest age group (15 - 24 years) as reference group, odds of current tabocacco use were significantly lower as age group increased for Indonesia, Malaysia, Romania and Argentina; and it was in the opposite direction for Nigeria. By residence, the odds of current tobacco use was significantly higher in urban areas in Romania only. The higher educated individuals had significantly lower odds of current tobacco used among Indonesians and Malaysians, There was no significant association between education and current tobacco use in argentian. In Nigeria, those with less than selondary school education had higher odds of current tobacco use than educated at collage or above.

For wealth index, significant correlates of current tobacco use were seen in Indonesia, Malaysia and Romania; i.e. decreasing trend of tobacco used with increasing wealth. Nigeria, There were no significant associations with wealth index and current tobacco use in Argentina or Nigeria. Significant negative association between current tobacco use and awareness of adverse health consequences of smoking were found in all five countries except Argentina.

\section{Discussion}

We use the data from five countries that participated in the phase II of Global Adult Tobacco Survey to analyse the demographic and socioeconomic characteristics associated with current tobacco used among smokers living in upper-middle income countries (Argentina, Malaysia and Romania) and lower-middle income countries (Indonesia and Nigeria) (World Bank). These five countries had a total population of 496.1 million; of which $16.2 \%$ of the population ( 80.25 million) were current tobacco users (Global Adult Tobacco Survey: Indonesia Report, 2011; Tee at al., 2012; Global Adult Tobacco Survey, Romania 2011; Global Adult Tobacco Survey, Argentina 2012; Global Adult Tobacco Survey: Nigeria Country Report, 2012). The overall prevalence of current tobacco used varied significantly in the five countries; from $5.5 \%$ in Nigeria to $35.7 \%$ in Indonesia. The use of smokeless tobacco in these five countries was rather low; ranging from $0.2 \%$ in Argentina to $1.9 \%$ in Nigeria which concurred with findings of other studies (Gary et al., 2012; Palipudi et al., 2012).
Our study found that tobacco used was predominantly higher among men in Indonesia, Malaysia and Nigeria; the prevalence of current tobacco use among women was rather low (1.1\% in Nigeria, 1.6 in Malaysia and 4.4\% in Indonesia). The considerably higher prevalence of tobacco use in men than women as observed in this study was consistent with many other studies (Imhonde et al., 2001; Xiao et al., 2009; CDC, 2009; Hosseinpoor et al., 2011; Gary et al., 2012; Kaleta et al., 2012; Lim et al., 2013; Gilani and Leon, 2013; Sreeramareddy et al, 2014; Palipudi et al., 2014). This gender disparity on tobacco used is higher in Asian countries such as Indonesia and Malaysia, as well as in African countries like Nigeria. Smoking among men in Indonesia, Malaysia and Nigeria are considered normal and socially appropriate; whereas smoking among women is associated with social stigma, i.e. considered as an unacceptable behaviour, and it met with strong cultural and social disproval (Imhonde et al., 2001; Reimondos et al., 2011; Tee et al., 2012; Palipudi et al., 2014). However, the gap of the gender disparity in tobacco use is much smaller in western countries as evidenced from findings in Argentine (Global Adult Tobacco Survey, Argentina, 2012) and Romania (Global Adult Tobacco Survey, Romania, 2011). The prevalence of smoking among men was rather high (29.4\% in Argentina, $37.4 \%$ in Romania); and the prevalence of smoking among women were approximately half that of men in Argentina (15.7\%) and Romania (16.7\%) respectively. This finding might be due to the fact that smoking cigarettes is one of the most socially acceptable health-risk behaviour in Romania (Global Adult Tobacco Survey, Romania, 2011). The higher rate of smoking among women in western countries could be that these women achieve more social and economic equality. In addition, smoking is very common among men in Central and Eastern Europe and disproportionately affects men globally (Gary et al., 2012). It is imperative to acknowledge that gender is the most consistently significant social influence on tobacco use and should not be treated as an overarching covariant. The gender disparity of tobacco use could not do away with the cultural and normative influence on male smoking especially in Asian and African countries. National tobacco control programmes in individual countries incorporate strategies that are gender-specific and develop gender sensitive policies and programmes to curb the high rate of tobacco use among men and hopefully to prevent a new epidemic among women; especially in countries where tobacco use is still low.

The odds of current tobacco use varied among different age groups in these five countries under study. The highest proportion of smokers in the upper-middle income countries of Argentina, Malaysia and Romania were in the 25-44 years age group; whereas the highest proportion of smokers in the lower-middle income countries of Indonesia and Nigeria were in the older age groups of 45-64 years and 65+ years respectively. Similar trends of tobacco used by age groups had been found in the World Health Survey on 48 countries to determine the social determinants of smoking in low- and middle-income countries (Hosseinpoor et al., 2011). The age-specific prevalence of smoking was found to be highest in the 
young adulthood (25-44 years) and middle age (45-64 years) in GATS countries (Palipudi et al., 2012; Gary et al., 2012). The lower prevalence of smoking in older age groups in Argentina, Malaysia and Romania might be due to an increased quit rate as a result of high awareness of the health consequences of smoking (Yang et al., 2010; Gary et al., 2012; Sansone et al., 2012; An et al., 2013). These findings suggest that tobacco control initiatives must be targeting at all age groups and customize for different age groups. Health promotion and education campaigns must be designed differently instead of using the onesize-fits-all to target the different age groups. The high prevalence of smoking in the older population in Indonesia and Nigeria is a cause for concern; this might suggest the acceptability of tobacco use and lack of smoking cessation among this population. Older population with weakened immune systems might lead to more comorbidities arising from tobacco use.

Tobacco use is persistently associated with lower socioeconomic status. Many studies have found that smoking was more common among those with lower education and income. Likewise, our results were consistent with numerous studies with the existence of social gradient in smoking behaviour among adults; i.e. the prevalence of current smoking was generally higher in lower socioeconomic groups. Education was found to be inversely associated with smoking in these GATS countries except for Argentina; those with the highest education attainment used the least tobacco. Our finding is supported by many other epidemiological studies elsewhere in examining the relationship between education and smoking (Siahpush et al., 2005; Stephen et al., 2008; Cuong, 2012; Lim et al., 2013; Thakur et al., 2013; Bhawna G, 2013; Sreeramareddy et al., 2014; CDC, 2014). Koning et al (2010) reported that with one additional year of education, the duration of smoking is reduced by nine months. This inversed association of smoking could be explained by the awareness and consciousness of one's health as one attains higher education. In contrast, lower and low education tobacco users are less likely to use smoking cessation facilities and there are more likely to have other smokers living with them (Zhu et al., 2010).

Another key determinant of inequality associated with tobacco use was wealth. It showed a clear inverse association with tobacco use in three countries; i.e. Indonesia, Malaysia and Romania. Our finding was consistent with that reported by Barbeau et al (2004), Laaksonen et al (2005), Armour et al (2008), Thakur et al (2013) and Bhawna G (2013) whereby low income is independently associated with higher rates of smoking. However, our finding was somewhat in contrast with the findings by Hosseinpoor et al (2011) whereby wealth was inversely associated with smoking in the low-income countries only.

The disproportionate number of smokers in lower income groups has led to the increased health inequalities between the poor and the rich. Persons with lesser education and lower-income/wealth are particularly burdened by tobacco use; they tend to use tobacco more, thus suffer and spend more, as well as leading to more deaths from tobacco use (CDC, 2009). The economic burden of tobacco use weighs heaviest on the poorest. On the other hand, persons with higher education attainment and higher incomes tend to avoid smoking initiation and use tobacco less. This might be due to the accessibility of information regarding the health risk of smoking (Pampel, 2008), as well as having the knowledge and skills which are important in making health behaviour choices including smoking (Mirowsky, 1998). In addition, they tend to live in a healthy and safe environment; thus has on average longer life expectancies and better overall health outcomes.

Alan Milburn, Secretary of State for Health, United Kingdom said "Smoking is the principal cause of the inequalities in death rates between rich and poor. Put simply, smoking is a public health disaster" (Richardson and Crosier). Research had shown the contribution of smoking to many preventable illnesses and premature death (World Health Organization, 2009; World Health Organization, 2011) as well as a major contributor to social inequalities (Jha et al., 2006; Marmot, 2006). Similar evidence was seen in the Mackenbach study, where the excess death in men with lower education due to smoking varied from 5\% in Madrid to 30\% in England and Wales (Mackenbach et al., 2004). In May 2013, the World Health Assembly endorsed the WHO Global Action Plan for the Prevention and Control of non-communicable diseases from 2013-2020 (World Health Organization, 2013b). One of the aims of the Plan is to achieve the voluntary global target of a $30 \%$ relative reduction in prevalence of current tobacco use in persons $\geq 15$ years. In order to achieve this said goal, it is vital to ensure that reducing social inequalities in smoking and its health consequences is to be made a public health and political priority.

Romania (a middle-income country) was the only country which showed higher prevalence of smoking among urban residents. Our result concurred with the surveys in 13 other GATS countries where urban residents had increased likelihood of smoking (Palipudi et al., 2012) and World Health Survey where tobacco used was generally higher among urban residents in middleincome countries (Hosseinpoor et al., 2011). The higher prevalence of tobacco use among urban residents could be that smoking is a socially more acceptable behaviour with fewer smoking restrictions among these urban populations. Hence, tobacco users from urban residency provide a potential target group for future tobacco control campaign.

We found significant negative association between current tobacco use and awareness of adverse health consequences of smoking in all five countries except Argentina. Those who were aware of the health consequences of smoking had a lower prevalence of smoking was in concordant with the studies by Yang et al (2010), Sansone et al. (2012) and An et al. (2013) whereby these smokers had more intentions to quit smoking. Similarly, lack of awareness of smoking health consequences was significantly correlated with heavy smoking among the Polish population (Kaleta et al., 2012). Greater awareness about the harms of tobacco use among current tobacco users are more likely to promote intentions to quit. 
The findings from this study have to be interpreted by taking into consideration of several limitations. Our analyses rely on self-reported smoking status without biomarker analysis of serum cotinine. However, selfreported smoking status has been found to be comparable with results tested for serum cotinine (Patrick et al., 1994; Vartiainen et al., 2002). There may be under reporting from female respondents especially from Malaysia, Indonesia and Nigeria where tobacco use especially cigarette smoking is not a social norm and socially undesirable; this may underestimate the true prevalence (Imhonde et al., 2008; Reimondos et al., 2011; Tee et al., 2012; Palipudi et al., 2014). Wealth index is based on a composite of household possessions which may differ by different countries; this may not present a true picture of wealth across the five countries. Another limitation of the study is that we did not include frequency and intensity of smoking, as well as percentage of household income spent on tobacco.

In conclusion, our study showed that the prevalence of smoking was higher among the socially and economically disadvantaged population; those with fewer years of education, low to lower-income and rural dwellers. In addition, annual mortality due to smoking or tobacco use in the five countries in this study ranges from 10,000 in Malaysia (Ministry of Health Malaysia, 2003) to 200,000 in Indonesia (Global Adult Tobacco Survey: Indonesia Report, 2011). Our findings suggest that development of effective anti-smoking programmes and tobacco control intervention targeting the socio-economically disadvantaged population are important; this will not only narrow the gap between different socioeconomic groups and reducing health inequalities, but in the long term would serve as the greatest potential for reducing the prevalence of smoking in the entire population - a winnable battle!

\section{Acknowledgements}

We would like to thank the Director General of Health Malaysia for his kind permission to publish this paper. The author would like to thank Jeremyu Morton and Luhua Zhao from office on Smoking and Health, centers for Disease control and Prevention, Atlanta, Georgia, USA for their Kind assistance with this manucript. The authors gratefully acknowledge the participating GATS country surveillance teams; WHO Regional Surveillance Officers, CDC Global Tobacco Control Branch; fieldworkers for their contributions and the survey respondents for their co-operation for making this study possible.

\section{References}

An DTM, Minh HV, Huong LT, et al (2013). Knowledge of the health consequences of tobacco smoking: a cross-sectional survey of Vietnamese adults. Glob Health Action, 6:18707, http://dx.doi.org/10.3402/gha.v6i0.18707.

Armour BS, Pitts MM, Lee CW (2008). Cigarette smoking and food insecurity among low-income families in the United States, 2001. Am J Health Promot, 22, 386-92.

Barbeau E, Krieger N, Soobader M (2004). Working class matters: socioeconomic disadvantage, race/ethnicity, gender, and smoking in NHIS 2000. Am J Public Health, 94, 269-78.

Bhawna G (2013). Burden of smoked and smokeless tobacco consumption in India - Resultsfrom the Global Adult Tobacco Survey India (GATS-India) - 2009-2010. Asian Pac J Cancer Prev, 14, 3323-29.

CDC (2009). "Cigarette Smoking Among Adults - United States, 2008”. MMWR, 58, 1227-32.

CDC (2014). "Current Cigarette Smoking Among AdultsUnited States, 2005-2012". MMWR, 63, 29-34.

Cuong NV (2012). Demographic and social-economic determinants of smoking behaviors: evidence from Vietnam. Econ Bull, 32, 2300-12.

Gary A Giovino, Sara A Mirza, Jonathan M Samet, et al (2012). Tobacco use in 3 billion individuals from 16 countries: an analysis of nationally representative cross-sectional household surveys. Lancet, 380, 668-79.

Global Adult Tobacco Survey Collaborative Group (2010a). Global Adult Tobacco Survey (GATS): Core Questionnaire with Optional Questions, Version 2.0. Atlanta, GA: Centres for Disease Control and Prevention.

Global Adult Tobacco Survey Collaborative Group (2010b). Global Adult Tobacco Survey (GATS): Sample Design and Sample Weight manuals, Version 2.0. Atlanta, GA: Centres for Disease Control and Prevention, 2010.

Global Adult Tobacco Survey Collaborative Group (2010c). Global Adult Tobacco Survey (GATS): Field Interviewer Manual, Version 2.0. Atlanta, GA: Centres for Disease Control and Prevention, 2010.

Global Adult Tobacco Survey Collaborative Group (2010d). Global Adult Tobacco Survey (GATS): Field Supervisor Manual, Version 2.0. Atlanta, GA: Centres for Disease Control and Prevention, 2010.

Global Adult Tobacco Survey Collaborative Group (2010e). Global Adult Tobacco Survey (GATS): Programmer's Guide to General Survey System Manual, Version 2.0. Atlanta, GA: Centres for Disease Control and Prevention, 2010.

Global Adult Tobacco Survey, Argentina (2012). Available http:// www.who.int/tobacco/surveillance/survey/gats/en. Accessed 2014 December 18.

Global Adult Tobacco Survey: Indonesia Report 2011. Available http://www.who.int/tobacco/surveillance/survey/gats/ indonesia_report.pdf. Accessed 2014 December 4.

Global Adult Tobacco Survey: Nigeria Country Report (2012). Available http:// nigerianstat.gov.ng/pages/download/157. Accessed 2014 December 18.

Global Adult Tobacco Survey, Romania. Available http:// www.ms.gov.ro/documente/Global Adult Tobacco Survey Romania 2011_9425_7779.pdf. Accessed 2014 December 18.

GH Tee, Fadhli Y, GS Sukhvinver, et al (2012). Report of the global adult tobacco survey (GATS) Malaysia. Ministry of Health Malaysia.

Gilani SL, DA Leon (2013). Prevalence and sociodemographic determinants of tobacco use among adults in Pakistan: findings of a nationwide survey conducted in 2012. Population Health Metrics, 11, 16.

Gilman SE, Martin LT, Abrams DB, et al (2008). Educational attainment and cigarette smoking: a causal association? Int J Epidemiol, 37, 615-24.

Global Tobacco Surveillance System (2009). Global Adult Tobacco Survey (GATS): Indicator Guidelines: Definition and Syntax. Atlanta, USA.

Hosseinpoor AR, Parker LA, Tursan d'Espaignet E, Chatterji S (2011). Social Determinants of Smoking in Low- and Middle-Income Countries: Results from the World Health Survey. PLoS One, 6, 20331. 


\section{Guat Hiong Tee et al}

Imhonde HO, Afolabi AO, Ehon A (2001). The influence of self-efficacy, duration of smoking and gender on perceived smoking cessation. Niger J Psychol, 18, 123-133.

Jha P, Peto R, Zatonski W, et al (2006). Social inequalities in male mortality, and in male mortality from smoking: indirect estimation from national death rates in England and Wales, Poland, and North America. The Lancet, 368, 367-70.

Kaleta D, Makwiec-Dabrowska T, Dziankowska-zaborszczyk E, Fronczak A (2012). Determinants of heavy smoking: results from the global adult tobacco survey in Poland (2009-2010). Int J Occup Med Environ Health, 25, 66-79.

Koning P, Webbink D, Martin NG (2010). The effect of education on smoking behaviour. new evidence from smoking durations of a sample of twins. CPB Discussion Paper 139; 902 2010. CPB Netherlands Bureau for Economic Policy Analysis.

Laaksonen M, Rahkonen O, Karvonen S, Lahelma E (2005). Socioeconomic status and smoking: Analysing inequalities with multiple indicators. Eur J Public Health, 15, 262-69.

Lim HK, Mohd Ghazali S, Cheong CC, et al (2013). Epidemiology of smoking among Malaysian adult males: prevalence and associated factors. BMC Public Health, 13, 8 .

Mackenbach JP, Huisman M, Andersen O, et al (2004). Inequalities in lung cancer mortality by the educational level in 10 European populations. Eur J Cancer, 40, 126-35.

Marmot M (2006). Smoking and inequalities. The Lancet, 368, 341-42.

Ministry of Health Malaysia (2003). Clinical practice guideline of tobacco use and dependence 2003. Ministry of Health Malaysia.

Mirowsky J, Ross CE (1998). Education, personal control, lifestyle and health: a human capital hypothesis. Res Aging, 20, 415-49.

Palipudi KM, Gupta PC, Sinha DN, et al (2012). Social determinants of health and tobacco use in thirteen low and middle income countries: evidence from global adult tobacco survey. PLoS One, 7, 33466.

Palipudi K, Rizwan SA, Sinha DN, et al (2014). Prevalence and sociademographic determinants of tobacco use in four countries of the World Health Organisation: South-East Asia region: findings from global adult tobacco survey. Indian $J$ Cancer, 51, 24-32.

Pampel F (2008) Tobacco use in sub-Sahara Africa: estimates from the demographic health surveys. Soc Sci Med, 66, 1772-83.

Patrick DL, Cheadle A, Thompson DC, et al (1994). The validity of self-reported smoking: a review and meta-analysis. Am J Public Health, 84, 1086-93.

Reimondos A, Utomo ID, McDonald P, et al (2010). The 2010 greater jakarta transition to adulthood survey, policy background No. 2 smoking and Young Adults in Indonesia.

Richardson K, Crosier A. Smoking and health inequalities. Health Development Agency, London; ISBN 1-84279065-X.

Sansone GC, Raute LJ, Fong GT, et al (2012). Knowledge of health effects and intentions to quit among smokers in india: findings from the tobacco control policy (TCP) india pilot survey. Int J Environ Res Public Health, 9, 564-78.

Siahpush M, Heller G, Singh G (2005). Lower levels of occupation, income and education are strongly associated with a longer smoking duration: multivariate results from the 2001 australian national drug strategy survey. Public Health, 119, 1105-10.

Sreeramareddy CT, Pradhan PM, Mir IA, Sin S (2014). Smoking and smokeless tobacco use in nine South and Southeast Asian countries: prevalence estimates and social determinants from Demographic and Health Surveys. Population Health
Metrics, 12, 22.

Tee GH, Hairi NN, Hairi F (2012). Attitudes towards smoking and tobacco control among pre-clinical medical students in Malaysia. Int J Tuber Lung Dis, 16, 1126-8.

Thakur JS, Prinja S, Bhatnagar N, et al (2013). Socioeconomic inequality in the prevalence of smoking and smokeless tobacco use in India. Asian Pac J Cancer Prev, 14, 6965-69.

Vartiainen E, Seppala T, Lillsunde P, Puska P (2002). Validation of self-reported smoking by serum cotinine measurement in a community-based study. J Epidemiol Community Health, 56, 167-70.

World Health Organisation (2005). WHO Framework Convention on Tobacco Control. Geneva: World Health Organisation.

WHO Report on the global tobacco epidemic, 2008: the MPOWER package (2008). Geneva: World Health Organization. Available http://www.who.int/tobacco/ mpower/mpower_report_full_2008.pdf. Accessed 2014 December 4.

World Health Organisation (2009). Global health risk: mortality and burden of disease attributable to selected major risks. Available http://www.who.int/healthinfo/global_burden_ disease/GlobalHealthRisks_report_full.pdf.Accessed 2014 December 4.

World Health Organisation (2011). WHO report on the global Tobacco epidemic, 2011: warning about the dangers of tobacco. Geneva: World Health Organisation.

World Health Organization (2013a). WHO Report on the Global Tobacco Epidemic, 2013: Enforcing Bans on Tobacco Advertising, Promotion and Sponsorship. Geneva: World Health Organization.

World Health Organisation (2013b). Global action plan for the prevention and control of noncommunicable diseases 20132020. World Health Organisation. http://apps.who.int/iris/ bitstream/10665/94384/1/9789241506236_eng.pdf?ua=1. Accessed 2015 February 18.

World Bank. Countries and Economies. Available http://data. worldbank.org/country. Accessed December 4, 2014.

Xiao F, Robson P, Ashbury F, Hatcher J, Bryant H (2009). Smoking frequency, prevalence and trends, and their sociodemographic associations in Alberta, Canada. Can J Public Health, 100, 453-58.

Yang J, Hammond D, Driezen P, Fong GT, Jiang Y (2010). Health knowledge and perception of risks among Chinese smokers and non-smokers: findings from the Wave 1 ITC China Survey. Tob Control, 19, 18-23.

Zhu SH, Hebert K, Wong S, Cummins S, Gamst A (2010). Disparity in smoking prevalence by education: can we reduce it? Glob Health Promot, 17, 29-39.s 